\title{
The Value of Arts and Its Force: The Artistic Value and the Art Market
}

\author{
Xiaowen Zhang \\ The Faculty of Art, University of Melbourne, Melbourne, The State of Victoria, VIC 3010, Australia \\ *Corresponding author. Email: xiaowzhang@student.unimelb.edu.au
}

\begin{abstract}
The artistic value of an artwork is formed by various aspects, and it is noticeable that artistic value has an crucial status in the art world. The main goal of this essay is to give an overview of the artistic value of artworks by interpreting the subdivisions of values that constituted it, list factors that would impact on the valuation of the artworks' value, and analyze the examination techniques used for the valuation process. Also, the discussion of artworks' marketing value which would be impacted by artistic value is included in this essay. However, the factors that would make the marketing value of the artworks fluctuate, which are analyzed in this essay, are not ensured to be used for markets except Italian contemporary art market, whereas they can be taken as references.
\end{abstract}

Keywords: Value, Artistic value, Marketing value, Artworks, Techniques

\section{INTRODUCTION}

Artistic value is a crucial subject to be discussed in the art world. An artwork with high value could be sold in a sky-high price by auctioning or through art galleries; or it could be exhibited in the museums or galleries as a masterpiece. All in all, the value of artworks decides how they would be treated by art market participants. Nevertheless, the artistic value of arts is hard to define since the valuation work is complex. The valuation of an artwork is a collection of various aspects. This work involves two parts: the aesthetic value and cultural significance. The latter term includes the techniques and materials for creating artworks, the rarity of the material, authenticity, conditions of the work, and reputation of the artist. Furthermore, the artistic value can impact on its marketing value directly, which means all of these valuation categories can determine the price or the popularity of the artwork in the marketplace. It is worth noting that the terms of the artistic value and the aesthetic value should be distinguished in this essay since they are argumentative. The aesthetic value should be an embranchment of the artistic value. As for the cultural significance, it is suggested by Plante, Free, and Andon to be as an important factor in the valuation, which makes the valuation harder due to the subjectivity [9]. This is defined by a term of "quality uncertainty". This essay is to discuss the artistic values of artworks through analyzing the valuation aspects that mentioned above, and then move on to how these values are crucial to its marketing value and the art market. The topic would be interpreted continuously and thoroughly with evidences support.

\section{THE IMPACT FACTORS ON THE VALUATION OF THE ARTISTIC VALUE}

\subsection{Aesthetic Value}

The artistic value of artworks means the value of a work of art depending on its features and meaning. Some individuals would say that the artistic value of an artwork is consistent with the aesthetic value since aesthetically, an artwork is for appreciation. Nevertheless, Stecker mentioned propositions about this argument that valuable artworks could have a low aesthetic value and their value as artworks can also be existed when they are not lacking the aesthetic value [10]. In this essay, this assertion would be continued by taking aesthetic value as a part of the artistic value. The aesthetic value of an artwork could be subjective. Goldman raised a perspective that individuals should experience the aesthetic value of the artworks personally since it is changeable depending on the environment, the viewers, and the differentiated manner they apply for appreciating; also, the aesthetic value is only existing for individuals to appreciate [4]. This makes the aesthetic value an uncertain factor on the process of value examination. It 
is caused by the lack of unified standards of valuation, since viewers and inspectors have their own perspectives to perceive the aesthetic values of the artwork. While another statement has been claimed by Kaufman about the necessity of being objective toward the examination of values made by critics [5]. Kaufman states that the valuations made to the artworks by critics are usually based on their own tastes which are subjective and cannot become normative force therefore [5]. Indeed, it is indisputable that the aesthetic value is a subjective thing since either viewers or critics have diverse thoughts and tastes. But if the aesthetic value needs to be a part of the artistic value from a broader perspective instead of thinking it in a small scope personally, an objective valuation criteria is needed as a significance part to the valuation work. In consequence, the public could understand it in a normative sense, and the work could be comparable to others in the marketplace beyond the subjective judgment.

\subsection{Cultural Significance}

\subsubsection{Artist's reputation}

The cultural significance is another constituent part for the valuation process. According to Plante, Free, and Andon, the cultural significance means the degree that the artists and their artworks contribute to the history culturally, and the valuation methods also vary according to different artworks [9]. Works created in different time periods would represents different cultures and meanings by corresponded social norms and contexts. In addition, the cultures and meanings are also involved with the artists actions to the art network. The meaning of aesthetic value is about the work itself, whereas the cultural significance is taking the whole society, the time period, the historic contexts, and the history background of the work as a part of the value. This is a broader perspective to view the value of artworks. This essay will provide a further concept to this idea of cultural significance, and identify the embranchments of valuation aspects under this term. The most momentous part of the cultural significance is the reputation of the artists. McGonigal gives the conclusion to the relationship between the artist's reputation and the value of the artworks by the general view, that is, one artwork created by a more moral artist could have higher value than another similar work which is created by a less moral artist [6]. The value of an artwork would fluctuated with the artists' reputation instead of the work itself which is about the appearance or the techniques used for creation. Reputation of the artist is a part of the cultural significance which is also known as the history background information of the artwork.

\subsubsection{Visual examination and scientific detection}

The second subject related to the cultural significance includes three parts that need to be detected through visual and scientific detection. These three parts are the techniques and materials used for creation of the work, authenticity, and the physical and chemical conditions of the artwork. The techniques refer to the methods and materials the work was created. The characteristics of the techniques can be the traits for inspectors to valuate the genre and period of the paintings easier. As for painting, Barrett and Stulik illustrated four kinds of techniques for creating specific categories of painting. The basic technique refers to the brush strokes that are individually painted onto the surface so the pigments would not blend together, which can be represented by the tempera paintings by the Italian Trecento. Secondly, the transparent oil techniques are widely used for the Flemish and early Netherlandish paintings, and it is to cover a thin layer of transparent oil onto the underlayer of the painting. The highlighting with impasto white is the third technique which is remarkable in the Baroque paintings and is to cover the painting with a heavy impasto white layer. Lastly, the direct surface blending would blend the pigments together to create the contrast of highlight and shadow, which can be found in the Neoclassicist paintings [1].

In addition, color is another consideration to the value. According to Ball, some colors of pigments were hard to obtain in the Middle Ages and the Renaissance [2]. Pigments are particularly important to a work of art because of the influence it has on the painting's quality. However, some pigments were rare in the era they were created, which increased the value of the work itself on the level of cultural significance. Other than the colors (pigments), supports and mediums would also be recognized as creating materials for the valuation process. The techniques and materials could be parts of the value of the artworks, and in the mean while the identification of them could be a method of detecting for the authenticity as the visual examination process. Other than this visual examination, scientific techniques are also adopted for the detection of the authenticity by professional inspectors. In terms of artworks, there are three aspects that need to be detected through techniques. They are the identification of the original unaltered parts of the painting, authenticity, and the detailed physical and chemical structure of it. These would be detected by various lights and methods, for instance, UV light, UV photography, false color infrared photography, X-ray radiography, X-ray fluorescence spectrometry (XRF), and several microchemical methods [1]. Having gone through multiple times of restorations, some of the original parts of the painting might be disrupted and recovered with new techniques that differ from the artist's techniques to a certain extent. The restoration, as a process of removing and adding things to a meaningful historic work of art, can impact on the value of the artwork greatly with its quality. Therefore, detecting the 
restoration quality by scientific techniques is essential and crucial for valuating the work.

\section{ARTISTIC VALUE AND MARKETING VALUE}

\subsection{Auction pricing}

The artistic value of the artworks is crucial to the art market since it could determine the marketing value of artworks directly. Western paintings will be taken as examples for the discussion here. Besides the timing and factors that related to the auction houses and the market itself, the pricing of the Italian contemporary painting at auctions is mainly depending on three aspects of the values mentioned in the previous paragraphs: the artist identity (reputation), physical structure (authenticity), artistic and sale characteristics of the work (aesthetic value, techniques, and materials) [7]. This research result on Italian contemporary painting could be taken as reference for the auction pricing in other genres of painting in global auction market. As for the artist identity, except from having positive reputation, the artist's death is another aspect that could increase values on the grounds of Marinelli and Palomba's claim [7]. It can be inferred that once the artist has died, the rarity, the value, and the pricing of his or her paintings would increase in consequence since it is impossible to collect the dead artist's paintings in the future.

For the physical characteristics, the value of the painting could also be added through popularity. The painting can be auctioned by a high price if it was exhibited and available in the market before and owned by a private collector and released again years later. The price can also depend on the numbers of previous owners [7]. Furthermore, the cost of the pigments, a kind of material for creation, is also a factor to the auction pricing. Due to the rarity of some specific colors of pigments mentioned previously, the expensive costs of the pigments add the perceived value of the painting itself, which makes its auction pricing higher than the others. Also, paintings with high contrastive colors and those by artists who take colors as their main objection of creating, could be more valuable at auctions [8].

\subsection{Social and marketing value}

However, the artistic value brings about the other two ranges of value to the artworks: the social value and the marketing value. The artistic value and the art market are interacted. The market is a channel for the artist's thoughts which are infused into their works to be spread. The exhibiting of artworks through the channel of art market allows the public to receive more information about art, culture, and the history through the cultural significance value, and also provides chances for them to cultivate their tastes by the aesthetic value. Botti indicates that desiring for knowledge is the main factor that motivates people to visit art institutions [3]. This attracts the public to develop more comprehension to artworks and forms the social value consequently. On the one hand, the artistic value brings marketing value in the process of the spreading and circulating of the artworks in the art market. The creation of traditional visual artworks is to represent the concepts of the artists instead of creating them for a high marketing value [3]. On the other hand, the marketing value would also involve automatically as the artistic value disseminate in the art market among participants. The marketing behaviors are related to the needs of the art market participants, such as Functional (cultural) needs - desires for knowledge, Symbolic needs - showing personalities by consumed product, Social needs - topics for conversations on building social relationship, and Emotional needs feelings and fun [3]. By satisfying these needs, benefits to the art consumers by artworks are created and the artwork's marketing value is brought eventually.

\section{CONCLUSION}

In conclusion, this essay gives a fundamental sense of the term of artistic value and the constituents of it. Artistic value contains many subdivisions to resemble the criteria of the valuation work which would be detected thoroughly by both visual and scientific examinations to decide the artwork's value. Besides, the significance of the artistic value to the art market cannot be neglected since it could impact the pricing of the artworks at auctions or on other transaction occasions. Nevertheless, the research about the impacts of artistic value on the transaction pricing is not ensured in this essay. It can be applied by marketplaces outside the Italian contemporary arts and needs to be verified further. This scope of studies can be continued in the future to find out what artistic values would impact on the pricing of historic artworks in the global market.

\section{REFERENCES}

[1] Barrett, S., \& Stulik, D. C. An integrated approach for the study of painting techniques. A. Wallert, E. Hermens, \& M. Peek (Eds.), Historical Painting Techniques, Materials, and Studio Practice, 1995, pp. 6-11, Getty Conservation Institute, ISBN: 9780892363223.

[2] Ball, P., \& Earth, B. The Invention of Colour, 2008, Londres: Vintage.

[3] Botti, S. What Role for Marketing in the Arts? An Analysis of Arts Consumption and Artistic Value. International Journal of Arts Management, 2(3), 2000, pp. 14-27. From: http://www.jstor.org/stable/41064697. 
[4] Goldman, A. H. The Experiential Account of Aesthetic Value. The Journal of Aesthetics and Art Criticism, 64(3), 2006, pp. 333-342. From: http://www.jstor.org/stable/3700565.

[5] Kaufman, D. A. Normative Criticism and the Objective Value of Artworks. The Journal of Aesthetics and Art Criticism, 60(2), 2002, pp. 151166. From: http://www.jstor.org/stable/1520013.

[6] McGonigal, A. Art, Value and Character. The Philosophical Quarterly (1950-), 60(240), 2010, pp. 545-566.

From: http://www.jstor.org/stable/40660453.

[7] Marinelli, N., \& Palomba, G. A model for pricing Italian Contemporary Art paintings at auction. The quarterly Review of Economics and Finance, 51(2), 2011, pp. 212-224. From: https://doi.org/10.1016/j.qref.2011.02.001.

[8] Pownall, R. A. J., \& Graddy, K. Pricing color intensity and lightness in contemporary art auctions. Research in Economics, 70(3), 2016, pp. 412-420. From: https://doi.org/10.1016/j.rie.2016.06.007.

[9] Plante, M., Free, C., \& Andon, P. Making artworks valuable: categorization and modes of valuation work. Accounting, Organizations and Society, 91, 2021, pp. 1-18. From: https://doi.org/10.1016/j.aos.2020.101155.

[10] Stecker, R. Artistic Value Defended. The Journal of Aesthetics and Art Criticism, 70(4), 2012, pp. 355362. From: http://www.jstor.org/stable/4349653. 